\title{
"PENSAMIENTO EN LEÑA Y PIEDRA". LA CIUDAD IDEAL EN LA ODISEA DE KAZANTZAKIS Y LA TRADICIÓN DEL UTOPISMO GRIEGO ANTIGUO
}

\author{
Mariano Nava Contreras \\ Universidad de Los Andes, Mérida, Venezuela.
}

Resumen: La tradición utopista antigua es muy vasta. Comienza con Homero y la isla de los feacios y Hesíodo y la edad de oro. Sigue con poetas arcaicos, como Píndaro. Pasa incluso por poetas cómicos. Pero con Sócrates se vuelve un problema central de la filosofía: encontrar la forma de construir una sociedad justa y feliz. Fundamental en el utopismo antiguo es la República de Platón. Al utopismo platónico rinde tributo la Odisea de Kazantzakis: contempla la abolición de la familia y de la propiedad privada; establece el amor libre. Concibe al legislador como educador del pueblo. Con Platón, con la obra de Moro, con las de Yevgeni Zamiatin, Aldous Huxley, Ray Bradbury, George Orwell, Kazantzakis en la Odisea contrajo deudas innegables; también con su tiempo y su lugar.

Palabras clave: Utopismo - Odisea de Kazantzakis - Utopismo Antiguo - Filosofía Griega - Literatura griega moderna

\section{"THOUGHT IN WOOD AND STONE". THE IDEAL CITY IN THE KAZANTZAKIS' ODYSSEY AND THE TRADITION OF ANCIENT GREEK UTOPISM.}

\begin{abstract}
Abastract: The ancient utopian tradition is very vast. It begins with Homer and the island of the Phaeacians and Hesiod and the golden age. Follow with archaic poets, like Pindar. It even passes by comic poets. But with Socrates it becomes a central problem of philosophy: finding a way to build a just and happy society. Fundamental in ancient utopism is Plato's Republic. To Platonic utopism, Kazantzakis' Odyssey pays tribute: it contemplates the abolition of the family and private property; set free love. It conceives the legislator as an educator of the people. With Plato, with the work of Moro, with those of Yevgeni Zamiatin, Aldous Huxley, Ray Bradbury George Orwell, Kazantzakis in the Odyssey he contracted undeniable debts; also with its time and place.
\end{abstract}


Keywords: Utopism - Kazantzakis' Odyssey - Ancient Utopism - Greek Philosophy - Modern Greek Literature

Recibido: 27.12.2020 - Aceptado 23.1.2021

Correspondencia: Mariano Nava Contreras

Email:marianonava@gmail.com

Licenciado en Letras Mención Lenguas y Literaturas Clásicas,

Universidad de Los Andes. Mérida, Venezuela.

Doctor en Filología Clásica, Universidad de Granada.

Ap. Postal $\mathrm{N}^{\circ} 20$. IPOSTEL.Humbolt Mérida 5101 Venezuela

ORCID ID: 0000-0001-8156-741X

Tres pajarillos están posados en lo alto del atalaya de la ciudad; uno mira a lo lejos, hacia el mar; el otro, al valle desierto, el tercero, el mejor, salta en la entraña del hombre.

Nikos Kazantzakis, Odisea, XVI 1-3

1 final de la rapsodia XIV de su Odisea, Kazantzakis muestra a
Odiseo agachado sobre el suelo, esbozando con guijarros en el
barro uno de sus proyectos más queridos: fundar una ciudad.

...recoge piedrecillas y con un poco de tierra amasa espeso barro y rápido señala sobre el suelo lo que entreteje su espíritu:

En el medio la torre, la atalaya, y en torno las casas, Y alrededor la muralla dentada, tapia de senos-torreones....... Así, doblado, plantaba en la tierra el edificio de la fantasía, y a medida que la espora de la ciudad arraigaba, su espíritu se aliviaba, la arcilla cobraba vida, las casas desbordaban hombres, se vuelven madres las piedras todas, amamantan a sus hijos, brillan los guijarros cual jóvenes desnudos y juegan a los tejos y se levanta el Dios en forma de humo, estandarte de la brisa.

$(\mathrm{XIV} 1279-1291)^{1}$

1 Todas las citas de la Odisea de Nikos Kazantzakis están tomadas de la traducción de Miguel Castillo Didier, Santiago de Chile, 2013. 
No obstante, lo que se cuenta en las primeras rapsodias del poema es también la historia de cómo lentamente la idea va cobrando forma en la mente de Odiseo. Ha conspirado en Creta contra un senil Idomeneo y ha instigado a una revolución contra su reinado decadente (rapsodias VI-VIII). De ahí pasa a Egipto, azotado por el hambre y la miseria, que también es sacudido por otra revolución (X). Odiseo participa en ella, aunque no del todo convencido, junto al artesano Gérakas, el aldeano Escarabajo y el revolucionario Nilos (que no es otro que Lenín). La revolución en efecto fracasa (XI), Odiseo es apresado y poco después liberado. Entonces parte en una barca Nilo arriba. Desea proseguir, con sus seguidores, a través del desierto (XI) hasta encontrar un lugar donde fundar una ciudad y establecer una sociedad perfecta donde imperen el bien y la justicia ${ }^{2}$. Pero antes se retirará durante siete días a una montaña para meditar sobre la forma de conseguirlo (XIII-XIV).

\section{El utopismo en la Grecia antigua}

Mucho antes de que Tomás Moro acuñara su nombre en 1516, la utopía existía como uno de los principales motivos de la literatura y del pensamiento en la antigua Grecia. La descripción de lugares remotos, ideales y felices cuyos habitantes viven solazantes y despreocupados será una constante, primero de la literatura, después de la filosofía de los antiguos griegos. En la Ilíada, Homero cuenta cómo Zeus empuja con sus vientos las naves del troyano Héctor, que llega a divisar de lejos el país de los tracios, "criadores de caballos", así como el de los misios y el de los "magnánimos" hipomolgos, "que se mantienen de leche", y el de los abios, "los más justos de los hombres"3. En otro lugar, cuando el cojo Hefesto elabore el nuevo escudo con que Aquiles vuelva a combate, el poeta nos contará cómo el arma estaba decorada con fino arte de orfebre que mostraba dos ciudades, la una en paz y la otra en guerra, prodigándose en las bondades de aquélla ${ }^{4}$.

Es sin embargo en el relato de viajes por excelencia, la Odisea, donde

$2 \quad$ Kaz. Od. XIV 1129-1136: "Dijo, y tembló en su pensamiento y en su cabeza se alzó / una elevada fortaleza y refulgió a la luz, con muros y portales, / con sus grandes comandos en torno, los vigilantes atalayas. / ya se arraigaban en el hondo cerebro las casas, los jardines / y los infantes pequeños que mamaban, los mozos que alzan el disco, / y las leyes de piedra que están, cual ancianos, sobre las murallas, / y unas sostenían la balanza y la espada, y otras, una rama de mirto; / y se regocijó el varón-de-múltiplestormentos de ver lo mil-veces-deseado".

3 Il. XIII 1-7. En adelante, nos servimos de la traducción de LENS TUERO, J. y CAMPOS DAROCA, J., Utopías del mundo antiguo. Antología de textos, Madrid, 2000. 
el imaginario homérico se explaya en las descripciones de los más apartados rincones del furioso ponto a donde va a parar, errante y vagabundo, el sufrido rey de Ítaca en trabajoso retorno. Es así como tenemos noticias de la isla de Ogigia, donde mora la ninfa Calipso ${ }^{5}$, del País de los Feacios ${ }^{6}$, del de los cicones y el de los lotófagos ", o del de los "arrogantes" Cíclopes, que "no tienen ni asambleas que dan consejos ni leyes, sino que viven en las cumbres de los elevados montes" ${ }^{8}$.

Pero no será Homero el autor de la utopía arcaica más influyente. En un célebre fragmento de Trabajos y días, Hesíodo nos va a contar cómo en el principio de los tiempos habitó la tierra una raza áurea de hombres felices. Estos primeros hombres "vivían como dioses, con el corazón libre de preocupaciones, lejos y apartados de penalidades y miserias; y no estaban sometidos a la miserable vejez, sino que, siempre sin alteración en piernas y brazos, disfrutaban en fiestas, lejos de todos los males; morían como dominados por el sueño". Tiempo después, cuando esta raza se hubo extinguido, advino otra "estirpe muy inferior, de plata, no equiparable a la de oro ni en conformación del cuerpo ni en inteligencia". Ésta a su vez fue sustituida por otra aún inferior, la de bronce, y ésta por la de los héroes, "más justa y de mejor índole". La raza de los héroes se extinguió en las míticas guerras de los griegos, y hoy se encuentra "con un corazón libre de preocupaciones, en las islas de los afortunados junto al Océano de profundos remolinos". Finalmente sobrevino una quinta estirpe, la peor de todas, la de hierro, que nunca cesará de "sufrir fatigas y miserias" 9, y que es la que habita nuestro triste mundo actual, la misma de la que aún formamos parte. El mito de la Edad de Oro, reelaborado por Ovidio en sus Metamorfosis ${ }^{10}$, ejerció importante influencia en la conformación del imaginario utópico antiguo, y más acá, gracias a la popularidad y difusión que tuvo entre los autores renacentistas, en los Cronistas de Indias.

Otros poetas arcaicos abundaron también en descripciones utópicas. Así Píndaro, en su Olímpica II, nos habla de las maravillas de estas Islas de los Afortunados, donde "en iguales noches siempre y en iguales días gozando

\begin{tabular}{ll}
\hline 5 & Od. V 54-74. \\
6 & Od. VI 149-205. \\
7 & Od. IX. \\
8 & Od. IX 105-141. \\
9 & HES. Op. 106-201. \\
10 & OV. Met. 89-151. \\
236 &
\end{tabular}


del sol, los buenos reciben una vida menos fatigosa" ${ }^{11}$. Asimismo, en la Pítica x nos cuenta cómo los felices habitantes del País de los Hiperbóreos, "tras coronar sus cabelleras con laurel espléndido, banquetean gozosamente. Ni las enfermedades ni la vejez funesta penden sobre esta sagrada raza. Sin fatigas viven ni batallas, una vez que han escapado a la Némesis severa" ${ }^{12}$. Estas descripciones de lugares óptimos y opulentos serán recuperadas para la historia por Heródoto una generación después, si así hemos de entender la descripción de la ciudad de Babilonia que está en el libro I de su Historia, pero sobre todo la del país de los "longevos" etíopes en el libro III ${ }^{13}$.

No fueron tales postales de Utopía motivo exclusivo de los líricos. También los poetas cómicos abundaron en estas descripciones. Un texto de Ateneo, en El banquete de los sofistas ${ }^{14}$, nos recuerda que comediógrafos como Cratino, Crates o Teleclides se burlaron en sus obras de estos mundos primitivos y felices. Lo mismo diremos de Ferécrates, quien en su comedia Los salvajes no deja de mofarse de semejantes estampas: "Nadie tenía entonces ningún esclavo llamado Manes o Secis, sino que las señoras de la casa tenían que hacer en persona todas las tareas domésticas..." ${ }^{15}$. Sin embargo, es en Aristófanes donde mejor se puede apreciar cómo el discurso utópico va dejando de pertenecer al ámbito de lo imaginario y lo literario, para adoptar la forma de propuestas políticas muy concretas, que el autor cómico revisa en clave satírica y paródica. Así, Las aves y Las asambleístas son mordaz crítica del pensamiento utópico y del imperialismo ateniense. En aquélla, dos ancianos, Pistétero y Evélpides, deciden dejar la ciudad y fundar una nueva junto a las aves, en medio del aire. En ésta, las mujeres de Atenas, capitaneadas por Praxágora, deciden dar un golpe de estado a los hombres y establecer una utopía feminista. Sabemos que Las aves obtuvo el primer premio en las Grandes Dionisíacas del año 514 a.C., justo en medio de la última empresa imperialista ateniense, cuando la ciudad intentó atacar Siracusa, aventura que, como sabemos, terminó en el más estrepitoso desastre.

A partir del giro humanístico introducido por Sócrates, el pensamiento utópico se volverá un problema central de la filosofía: la forma de construir racionalmente una sociedad justa y feliz. Según testimonio de Aristóteles, en rigor los primeros utopistas fueron Hipódamo de Mileto y Faleas de Calcedón.

11 PI. O. II 61-67.

12 PI. P. X 29-44.

13 HDT. I 98, III 17 ss.

14 ATH. Deip. VI 267 e-270 a.

15 Fr. $10 \mathrm{~K}-\mathrm{A}$. 
El primero "ideó la división de las ciudades y proyectó el trazado de El Pireo"16 a partir de un modelo estrictamente racional. Faleas de Calcedón fue, por su parte, el primero en proponer que las propiedades de los ciudadanos fueran reguladas por el Estado, de modo que todas fueran iguales ${ }^{17}$. Estas medidas pretendían evitar las desigualdades que entre los siglos vi y v a.C. eran motivo de numerosas revueltas sociales por todo el mundo helénico.

Sin embargo, la obra que va a marcar el nacimiento del pensamiento utópico será, sin duda, la República de Platón. Si es verdad que los tratados "acerca de la República" o "acerca de las formas de gobierno", Perì politeias, abundaron a lo largo de toda la filosofía postsocrática, y prácticamente no hubo filósofo de importancia que no abordara este capital problema, también es cierto que todo este subgénero filosófico se construyó sobre las bases del pensamiento platónico, muchas veces incluso en relación polémica. Así, ideas como la de la austeridad de los ciudadanos, la organización del espacio físico según un determinado modelo racional o la división de la sociedad como factor de equilibrio del poder, a más de heredadas, es verdad, fueron aquí maduradas y desarrolladas, para pasar a componer el acervo esencial de la reflexión utópica ${ }^{18}$. Sin embargo, como en casi todos los grandes temas de Platón, sus ideas sobre Utopía no se agotan en un solo diálogo, sino que se esparcen en uno y otro rincón de su obra. De este modo encontramos en el Timeo noticias del país de los atlantes, "una isla que era mayor que Libia y Asia juntas"19, si bien tendremos que buscar en el Critias la célebre descripción de la ciudad de los atlantes que tanto excitará la imaginación de navegantes españoles $\mathrm{y}$ exploradores modernos $^{20}$. Un último relato utópico será desarrollado en un diálogo ulterior, Las leyes, donde el filósofo desarrolle uno a uno todos los elementos canónicos de la utopía arcaica ${ }^{21}$, revisándolos cara incluso a

16 ARIST. Pol. 1267 b.

$17 \quad$ ARIST. Pol. 1266 a.

18 Como es de imaginar, la bibliografía acerca de la República de Platón es prácticamente inabarcable. Sin embargo, hasta el momento, no es posible hallar una lectura y análisis más completos que los que ofrece Julia Annas en su clásico trabajo An introduction to Plato's «Republic», New York-Oxford, 1981.

$$
\text { PL. Ti. } 23 \text { e- } 25 \text { d. }
$$

20 PL. Cri. 113 b-115. Cf. al respecto el clásico estudio de VIDAL-NAQUET, P., L'Atlantide. Petite histoire d'un mythe platonicien, Paris, 2005; así como el trabajo de PRADEAU, J.-F., "L'Atlantide de Platon, l'utopie vraie", Elenchos, 2001, fasc. 1, pp. 75-98. 
muchas de las posiciones que antes había sostenido en la República. Puede decirse que, con Platón, se verifica el tránsito de Utopía desde las regiones de lo fantástico y lo literario hacia las más escabrosas de la reflexión racional y lo político, estableciendo desde entonces una peligrosa relación con la realidad.

Puede decirse también que, a partir de la obra del Ateniense, toda la filosofía política en Grecia será, esencialmente, utópica. No será otra la lectura posible de textos como la Constitución de los lacedemonios de Jenofonte o la Política de Aristóteles, donde se vuelve una y otra vez sobre el recurrente problema de la construcción de la sociedad perfecta. Mucho menos será el caso de los tratados de los estoicos, ya en época helenística. Obras como la República de Zenón de Citio, fundador de la escuela del Pórtico, se inscriben en esta orientación. De hecho, Diógenes Laercio afirmaba que Zenón escribió su República "sobre la cola del perro", aludiendo a su innegable influencia cínica ${ }^{22}$. Plutarco afirmó por su parte que la obra había sido escrita "en contra de la de Platón" ${ }^{23}$. En realidad, los tratados acerca de la constitución ideal de la república, Perì politeîas, fueron tan abundantes por esta época que puede decirse que representan un subgénero filosófico que nace y se desarrolla a la sombra del celebérrimo tratado de Platón ${ }^{24}$.

\section{La fundación de la ciudad ideal en la Odisea de Kazantzakis}

En su poema, Kazantzakis rinde tributo a la vieja tradición del utopismo griego. La erección de la ciudad ocupa toda la rapsodia XV del poema, que ni Kimon Friar ni Castillo Didier dejan de titular, precisamente, "la ciudad ideal" ${ }^{25}$. Su emplazamiento no carece de simbolismo. Se trata de una "seca meseta" donde el héroe encontró un "peral silvestre" (XV 313-314) y a cuya izquierda "se abría la boca de una gran caverna" (XV 335). Allí vio como "un pájaro dorado con la pechuga pintada de sangre" entraba en la gruta y lo tomó

22 D.L. VII 1.

23 PLU. Stoic. Rep. 8, $1034 \mathrm{f}$.

24 Solamente para los Estoicos, de Zenón, además de su Politeîa, se conserva el título de un Acerca de las leyes; de Cleantes un Acerca de la monarquía, un Acerca del impartir justicia y un Político. De Perseo, discípulo de Zenón, conocemos los títulos de una República de los lacedemonios, un Acerca de la monarquía y de una obra antiplatónica, Contra las leyes de Platón. Igualmente de Esfero, discípulo de Cleantes, se conserva un Acerca de la república de los lacedemonios, un Acerca de la monarquía y otra obra de tema espartano, Acerca de Licurgo y Sócrates.

25 KAZANTZAKIS, N., The Odyssey, Translation into English verse, Introduction, Sypnosis and Notes by K. Friar, New York, 1958. CASTILLO DIDIER, op. cit. 
como señal (“el pajarero se alegró de que Dios le mandara un mensajero") ${ }^{26}$. Como bien nota Helena González Vaquerizo ${ }^{27}$, la descripción implica una "inversión del poema homérico", pues la autora tiene en mente la descripción del palacio de Alcínoo, rey de los feacios. En su huerto, recordamos, "no se pierde el fruto ni falta nunca en invierno ni en verano (...) la pera envejece sobre la pera, la manzana sobre la manzana, la uva sobre la uva y también el higo sobre el higo" 28.

En realidad, no se trata de la "inversión" del mito homérico, sino más bien de toda una constante en la tradición utópica antigua: la de la abundancia y felicidad del no-lugar. Es tradición que el país utópico sea de una extraordinaria fertilidad, con una configuración orográfica y geológica óptimas. Asimismo lo caracteriza la excelencia climática, la eukrasía ${ }^{29}$. Fértil no es solo el país de los feacios, sino también la tierra de la Edad de Oro y la Atlántida, lo que contrasta con el entorno desértico en que se erige la ciudad que funda Odiseo. En ese sentido, como nota González Vaquerizo ${ }^{30}$, el simbolismo del peral, árbol que crece en tierras agrestes y sin embargo produce dulces frutos, es notable ${ }^{31}$. El peral es el único árbol que crece en la "seca meseta" donde Odiseo fundará su ciudad. La pera, lo hemos visto, es mencionada entre los frutos que produce en abundancia el fertilísimo huerto del palacio de Alcínoo,

26 La escena recuerda el mito mexica de la fundación de México-Tenochtitlan. Según la Crónica mexicayotl, el dios Huitzilopochtli ordenó a los mexicas buscar en medio de un lago un lugar donde habría un águila posada sobre un nopal con una serpiente entre sus garras. En ambos relatos, que refieren una fundación mítica, resulta fundamental la imagen del ave y el fruto como señal que da fin a la peregrinación de un pueblo.

27 González Vaquerizo, H., "La ciudad ideal en la Odisea de Nikos Kazantzakis", Byzantion Nea Hellas, 32 (2013), 247-268.

28 Od. VII 117-120. Todas las citas de la Odisea de Homero están tomadas de la traducción de José Luis Calvo Martínez, Madrid, 2000.

29 Cf. nuestro trabajo "Politeia y utopía. Elementos para una poética de la utopía filosófica en la Grecia antigua”, en NAVA CONTRERAS, M., Estudios sobre pensamiento antiguo, Mérida, Venezuela, 2007, pp. 23-38. Cf. asimismo LENS TUERO, J., "La representación de la Edad de Oro desde Hesíodo hasta Pedro Mártir de Anglería", en GARCÍA GONZÁLEZ, J. y POCIÑA PÉREZ, A. (eds.), Pervivencia y actualidad de la cultura clásica, Granada, 1996, pp. 171-209.

30

Op. cit.

$31 \quad$ KAZ. Od. XV 315-518: “...erguido todo el año luchaba con valentía contra los elementos, / la sequía, el viento arremolinado, el gusano y el hielo, / y dentro de su corteza con paciencia iba tejiendo los frutos; / y ahora he aquí que se cubrió de flores y tiembla suavemente igual que una novia". 
en el país de los feacios. Otro elemento propio del utopismo antiguo que contrasta con las descripciones en el poema de Kazantzakis es la insularidad. En la tradición griega, el no-lugar suele estar localizado en una isla remota, así la isla de los feacios, la de Ogigia donde mora la ninfa Calipso, el país de los lotófagos, la isla de los cíclopes, la de los Afortunados o la Atlántida. Su aislamiento obviamente no es gratuito como elemento para realzar el contraste de la utopía con el resto del mundo. La "ciudad ideal" de Kazantzakis también se encuentra aislada en un lugar remoto, pero en medio de un desierto.

Hallado su emplazamiento, la fundación misma de la "ciudad ideal" merece una serie de consideraciones. Los elementos conducen a la construcción de un discurso mítico ${ }^{32}$, lleno de símbolos, rituales y prodigios que se narran entre los versos 399 y 474: esa madrugada, Odiseo clava entre las brasas llameantes de una fogata un largo cuchillo de mango negro. Después traza un círculo a su alrededor, que se interrumpe en cuatro puntos. El hoyo en el centro simboliza el alcázar ("la semilla de la ciudadela") y el templo ("justo en el medio está el Dios"). El círculo es la muralla que se extiende a su rededor ("en torno del castillo, la muralla con sus senos-torreones"), con puertas que se abren a los cuatro puntos cardinales. Durante un momento los compañeros admiran la refulgente cartografía trazada en el suelo. Después, cuando ya han grabado la incandescente imagen en sus mentes, Odiseo deshace con sus pies la fogata, acaso presagiando la vida breve y el terrible fin que tendrá la ciudad ${ }^{33}$. Ya está amaneciendo. A la luz de la Aurora, el arquero fundador lanza una flecha a cada uno de los cuatro puntos, saeteando los cuatro vientos: Boreas, Noto, Oriente y Poniente. Entonces sacrifica "seis gallos y seis pollos grandes" a los doce Olímpicos ${ }^{34}$, "los doce dioses que una vez, allá en las playas celestes, adoró con temor y certidumbre, y se avergonzó su espíritu". Es claro que ahora habla el poeta y el filósofo Kazantzakis. Finalmente, Odiseo abrirá su propia mano y regará con su sangre los cimientos de la ciudadela.

Cumplidos los rituales, sin mediar comienza la construcción de la ciudad:

32 El relato mítico de la fundación de las ciudades es un lugar recurrido de la historiografía antigua, como en el caso de Roma en el libro I de la historia de Tito Livio. Cf. igualmente supra, nota 26.

33 KAZ. Od. XV 416-417: “...y cuando la hubieron ya sembrado en su labrado pensamiento, / el arquero con su planta impetuosa la deshace”.

$34 \quad$ Aunque los gallos de pelea pudieron ser animales muy valiosos en la antigua Atenas, el sacrificio de este animal a los dioses era considerada como una ofrenda bastante modesta. Se tenía como sacrificio específico para algunos dioses, como Asclepio, según cuenta Platón al narrar los últimos momentos de Sócrates (PL. Fed. 118 a 7-8). 
Dijo, saltó de los cimientos y repartió la labor; un grupo a tallar las piedras, otro grupo a los bosques, y unos compañeros edifican juntos y otros salen de caza; las mozas amasan el pan, las ancianas con el condumio se las ven, y todos comienzan a entonar canciones de trabajo para aliviar el esfuerzo...

\section{La forma de la ciudad}

En la mejor tradición del utopismo antiguo, la "ciudad ideal" que funda Odiseo es mucho más que una aventura urbanística, una propuesta arquitectónica. Los antiguos griegos separaban muy bien los conceptos de ásty (la ciudad en su dimensión material, las calles, casas, murallas y demás edificios públicos) y de polis (la ciudad en su dimensión cultural e institucional) ${ }^{35}$. Que la ciudad es mucho más que sus calles, murallas y casas es una reflexión que puede remontarse a los tiempos de Alceo ${ }^{36}$. En la reflexión filosófica, ambos aspectos están profundamente relacionados, y ambas son caras de una misma realidad.

La "ciudad ideal" tiene, pues, una dimensión material ${ }^{37}$, como queda claro en algunos pasajes del poema, aunque no abunden los detalles. En el fragmento anterior (XV 492-496) se mencionan muy concretamente las labores de la construcción: los que tallan las piedras, los que cortan la madera, los que construyen los edificios. Sobre la disposición de sus calles y edificios se dice poco más que generalidades, quizás porque, fuera de los elementos necesarios, el resto son detalles que el poeta desdeña:

35 Cf. en este respecto nuestro trabajo Del concepto de polis entre los antiguos griegos, Mérida, Venezuela, 2009.

36 El poema, que se atribuye a Alceo, es transmitido por AEL. ARIST. Or. 46. $207=$ FOCIO Bibl. 248: "No son las piedras ni la madera, ni / las bien construidas murallas lo que hace las ciudades; / sino que donde haya hombres capaces de defenderse a sí mismos / allí habrán murallas y ciudades".

37 XIV 1261-1262: “...yo quiero palos y piedra, arcilla, trulla y hombres. / De otro modo no se edifica el alma aquí en la tierra y no madura el sueño". 
Dijo, y tembló en su pensamiento y en su cabeza se alzó una elevada fortaleza y refulgió a la luz, con muros y portales, con sus grandes comandos en torno, los vigilantes atalayas. Ya se arraigaban en el hondo cerebro las casas, los jardines y los infantes pequeños que mamaban, los mozos que alzan

y las leyes de piedra que están, cual ancianos, sobre las el disco, murallas, y unas sostenían la balanza y la espada, y otras, una rama de mirto; y se regocijó el varón-de-múltiples-tormentos de ver lo mil-veces-deseado (XIV 1129-1136) ${ }^{38}$

En el medio la torre, la atalaya, y en torno las casas, $\mathrm{y}$ alrededor la muralla dentada, tapia de senos-torreones

(XIV 1281-1282)

Sin embargo, que la planta de la ciudad es circular es quizás lo único que se explicita claramente:

Cuando hubo terminado y la Moira hubo delimitado todo el parten con hachas, azadones y palas... círculo, (XV 463-464)

Aunque muchos son los vestigios de antiguas ciudades prehelénicas e indoeuropeas cuya planta era circular ${ }^{39}$, no cabe duda en este caso de que se trata de un homenaje al utopismo platónico, cuyas propuestas recogen una visión psicológica de la concepción organicista del estado en el filósofo. Circular es la planta de la ciudad de los atlantes, con anillos concéntricos de tierra y agua unidos por puentes y canales. En el centro hay una isla con una eminencia, donde se sitúa la ciudadela con el templo de Poseidón, según se

$38 \quad$ Cf. supra nota 2.

39 Cf. MUÑOZ JIMÉNEZ, J. M., La ciudad como obra de arte. Las claves del urbanismo en la Grecia antigua, Madrid, 1996, pp. 25-27. 
describe en el Critias ${ }^{40}$. La ciudad perfecta ha de ser circular, pues el círculo es la forma geométrica perfecta (no tiene arriba ni abajo, ni comienzo ni fin), simboliza por ello la verdad y la inmortalidad ${ }^{41}$. Por otra parte, la ciudad es un microcosmos y su forma debe coincidir con la del cosmos, que es circular, como circular es el movimiento de los elementos que lo componen, según afirma Aristóteles en el De caelo ${ }^{42}$. Por lo demás, que la circularidad de la ciudad ideal es un lugar común entre los utopistas antiguos lo muestra la parodia que hace el personaje de Metón el Astrónomo en Las aves de Aristófanes ${ }^{43}$.

\section{La ciudad de Dios}

Fiel a la tradición antigua, la concepción de la ciudad se basa en una concepción previa del hombre, la cual a su vez descansa en una idea de Dios. Por eso la política, para los antiguos, tiene profundas raíces teológicas. La Odisea de Kazantzakis refleja fielmente estas concepciones. Es Dios quien ha inspirado a Odiseo la idea de fundar una ciudad, y Dios quien da los fundamentos éticos en los que va a establecer su sociedad. Pero ¿quién es este Dios de Kazantzakis, que como un "timonel" dirige semejante empresa colectiva?

El mismo Kazantzakis nos lo explica claramente en no pocos lugares de su poema. Cuenta que por las noches, cuando cansados de la fatigosa faena se retiraban a descansar los constructores de la ciudad, iba Odiseo junto a ellos a predicar "profundamente en la dura cabeza del pueblo sencillo al temible Señor":

$40 \quad$ Critias $115 \mathrm{~d}$ ss. Cf. asimismo VIDAL-NAQUET, P., L'Atlantide. Petite histoire d'un mythe platonicien, op. cit.

MUÑOZ JIMÉNEZ, op. cit., p. 31.

ARIST. De Cael. 268 b 12 ss.

43 A la nueva ciudad que han fundado Pistétero y Evélpides no tarda en llegar cantidad de demagogos y charlatanes tratando de sacar provecho. Entre ellos Metón el Astrónomo, que trata de "parcelar el aire y dividirlo en yugadas", ofreciendo un modelo de planta geométrica y circular para la nueva ciudad: "inscribiendo el círculo en un cuadrado, en medio estará la plaza, a la que llevarán vías directas y, como de una estrella, pues será circular, por todas partes saldrán de ella los rayos como espléndidas calles rectas" (ARISTOF. Av. 1004-1009). 
¡Hermanos, escuchadme; aguzad los cerebros, que quiero hablaros!

No está Dios sentado en las nubes ni está en el negro Hades

Ni como sombra vana atraviesa la fantasía del hombre, ¡sino que anda por la tierra estéril y junto a nosotros combate!

(XV 516-519)

" ¡Yo soy el grande y temible Dios, el jefe en la batalla!

¡No eres esclavo mío, no eres ya un juego entre mis manos

ni tampoco amigo fiel ni un hijo mío mimado;

sino mi sostén y compañero en el combate encarnizado!"

(XV 812-815)

Hermanos, no es todopoderoso; su sangre corre, tropieza por la tierra y Caronte le sigue la pisada.

......

¡Sangre, sudor y fuego, tierra y agua, eso es mi Dios!

No es pensamiento inmortal ni un pájaro del aire, sino que es carne mortal como la de nosotros, un cerebro trémulo que casi se apaga, corazón intranquilo y obstinado que tiembla como el del hombre;

¡y no sabe de dónde partió y hacia dónde se dirige!

El que de vosotros, compañeros míos, puede soportarlo,

que se quede;

mas los que piden en el mundo un Dios compasivo e inmortal, que al punto se levanten con sus familias y enseres y que partan

(XV 910-923)

No cabe duda de que se trata de un Dios hijo de los complejos tiempos vividos por el poeta, de su vida misma poblada de pasiones, militancias y desengaños políticos, pero también de sus lecturas. Un Dios cercano, dubitante y sufriente, compañero de "combate", en toda empresa humana que a priori se concibe como una confrontación. Y un Dios, muy especialmente, mortal, "carne mortal como la de nosotros", en una expresión que remite directamente a la influencia que sobre él ejerció el pensamiento de Nietzsche ${ }^{44}$. El Dios

44 Para la influencia de Nietzsche en el pensamiento de Kazantzakis, cf. FRIAR, K., "Introduction" to KAZANTZAKIS, N., op. cit., p. 21. Acerca de la idea de la "muerte de Dios” en Nietzsche, cf. SAVATER, F., Idea de Nietzsche, Barcelona, 2001, pp. 54-86. 
de Kazantzakis niega a la vez ambas tradiciones, la pagana y la cristiana ("ni sentado entre nubes ni en el negro Hades"), y quizás por ello mismo se convierte en referencia ética para los hombres. Pero a la vez, la "ciudad ideal" se convierte en un inexpugnable castillo interior, más cerca de Santa Teresa que de Platón, en cuyo alto alcázar se guarda Dios.

\section{El guerrero-legislador}

Los antiguos supieron pronto de la importancia pedagógica que ejerce la polis sobre el ciudadano, por eso el papel del legislador, el nomothêtés, es ante todo el de un maestro, un educador. Y esta enseñanza se manifiesta a través de la ley, la nómos, cuyo papel fundamental es el de formar a las almas virtuosas. Por eso, dice Aristóteles, el que es verdaderamente político "desea hacer a los ciudadanos buenos y obedientes a las leyes". También por eso "es evidente que el político debe conocer en cierto modo lo referente al alma", eidénai pôs tà perì psykhês ${ }^{45}$. Es lo que busca también Platón en su República, cuya influencia se muestra tan patente en el poema de Kazantzakis. En efecto, como afirma Jaeger en su Paideia, "el conocimiento socrático del bien en sí se concibe como un arte política, de la que hay que esperar toda la salvación" ${ }^{46}$. Así, en un pasaje que amalgama la tradición griega con la judeocristiana, al igual que Moisés, el Odiseo de Kazantzakis esculpirá en piedra diez mandamientos que entrega a su pueblo (XV 1160-1172), y en críptico gesto, deja una piedra vacía de palabras, en la que graba "una esbelta saeta, que lanza a lo alto, hacia el sol" (XV 1173-1174).

Profundo y concienzudo lector de Platón, en no pocos lugares de su poema Nikos Kazantzakis rinde justo tributo al filósofo ateniense. Su Odiseo es también un "espíritu-legislador" (XV 581), un "conductor-de-espíritus" (XV 852), un demiurgo -quizás en el sentido revolucionario del términoque desea, más allá de la fundación de una ciudad, establecer una sociedad basada en los más altos valores: "Él buscaba cómo al nacimiento, las bodas y la muerte / un fin más alto dar, más allá de lo humano" (XV 1079-1080); "Leyes ascendían y mandatos y órdenes y también esperanzas" (XV 570). Es el individuo virtuoso, el obrero, que sigue los mandatos de un Dios mortal hechos ley, el "Conductor", un Dios que "combate" a nuestro lado. Quizás por eso la "ciudad ideal" carece de nombre. Es lo que menos importa cuando la ciudad anónima se vuelve revelación:

45 ARIST. Eth. Nic. 1102 a 9 ss. Seguimos la traducción de María Araujo y Julián Marías, Madrid, 1994. 
En el pensamiento del arquero como un cuerpo se ordenaba la ciudad, y todo corría a una misma música y obedecía con docilidad al monarca invisible, de-grandes-aparejos, que estaba en sus entrañas (XV 545-548).

Es la norma fundamental imitar la ley del mundo, la ley que rige la ley de la naturaleza, el sabio principio que llamaban los estoicos homologeîn têi physei $^{47}$ :

Lo que la ciega-gusana madre tierra realiza sin conciencia, justo es que nosotros con ojos bien abiertos, con conocimiento lo queramos.

(XV 600-601)

Por lo demás, no son pocos los elementos de la sociedad platónica que se ven reflejados en la Odisea de Kazantzakis. Así la sociedad tripartita, dividida en artesanos, guerreros y filósofos, fuertemente jerarquizada ${ }^{48}$ :

...y ya en su pensamiento distinguíanse los buenos

trabajadores,

con las herramientas de la labor en la tierra, en los mares

y en el aire;

y sobre ellos los lanceros, de armas duras y crueles, que poseen las llaves de la valentía y el sello del honor; y en la cima, el fruto de todo el combate, los combatientes-delespíritu .

(XV 540-544)

47 "Vivir según la naturaleza”. Cf. Cic. De rep. III 33: "La ley verdadera es por tanto la recta razón en perfecta conjunción con la naturaleza".

48 Acerca de las connotaciones de la tripartición de la sociedad en demiurgos, guardianes y filósofos en el pensamiento platónico y el pensamiento político griego, cf. DESMOND, W., Philosopher-Kings of Antiquity, London, 2011. Para la República, cf. especialmente pp. 23-32. 
También el amor libre y la abolición de la familia, establecidos en la República ${ }^{49}$ y que se asocian a una tradición platónica que se remonta, al parecer, a los lacedemonios ${ }^{50} \mathrm{y}$ se extiende hasta los estoicos ${ }^{51}$ :

No quiere Dios hogares separados, ni puertas entrabadas.

Quien tiene mujer e hijos y animales en una casa cerrada, encierra a la virtud ociosa y asfixia a la deidad;

y el mundo no penetra en el umbral de su puerta.

En la ciudad de nuestro Conductor no hay hogares separados; quien quiera unirse en el amor con una niña, que la tome, y que vayan a lo hondo de la selva a gozar del gran rayo ¡y que de nuevo se separen a la aurora, antes de que el placer decaiga. (XV 550-557)

Igualmente la abolición de la familia ${ }^{52}$ :

Solo los viejos y las ancianas que vivan separados, descrédito de la humanidad, y que mueran todos luego, para que vuelvan a la tierra, para que coman y beban las raíces de la raza, y que los nietos florezcan

lejos de los padres de-sombra-pesada, no vayan a marchitarse sus corazones.

(XV 558-560)

49 PL. Rep. 457 a-458 d, 464 b: "No creo -repliqué- que se dude de su utilidad, ni de que sería el mayor de los bienes el que las mujeres sean comunes y que también sean comunes los niños, siempre que sea posible; pero pienso que sí dará lugar a muchas discusiones el asunto de si ello es posible o no".

50 JEN. Rep. Lac. I 8: "y si alguno no quería convivir con su mujer, pero deseaba tener hijos dignos de ser recordados, también esto [Licurgo] hizo que fuera legal, pues, con el consentimiento de su marido, podía tener hijos con aquella que le pareciera fecunda y sana".

51 Lo dice claramente Diógenes Laercio (VII 33): "Es dogma [de Zenón] que las mujeres han de ser comunes, de modo semejante a Platón, en la República".

52 Cf. supra, nota 46. 
Y de la propiedad privada ${ }^{53}$ :

...Dios es el único dueño;

derrumbaron las almas los vallados, aquí lo mío y lo tuyo, $\mathrm{y}$ todos laboraban fraternales, y todo repartían fraternalmente.

(XV 1096-1098)

Otro elemento propio del repertorio utópico se encuentra en el poema, y tiene que ver con el establecimiento de fiestas públicas en la ciudad ideal. Las fiestas públicas, la festividad, es un elemento esencial en la construcción del clima psicosocial que debe reinar en Calípolis, el no-lugar, la ciudad ideal. Su concepto se resume en una palabra griega que se mantiene como una constante en el relato utópico de los antiguos: hesykhia ${ }^{54}$, estado emocional que implica una vida tranquila y satisfactoria. Así, Hesíodo cuenta que, en la Edad de Oro, la dorada estirpe vivía "como dioses, con el ánimo libre de preocupaciones, sin fatiga ni miseria (...) se recreaban con fiestas ajenos a todo tipo de males" ${ }^{55}$. Asimismo en la Calípolis de su República, Platón dice que sus ciudadanos "banquetearán, recostados en lechos naturales de nueza y mirto, en compañía de sus hijos; beberán vino, coronados toso de flores, y cantarán laudes de los dioses, satisfechos con su mutua compañía" ${ }^{56}$. Y en Esparta, al caer el día los hoplitas comen juntos "después de cantar a los dioses de quienes hayan obtenido en los sacrificios auspicios favorables", según testimonio de

53 PL. Rep. 416 d-e: “Ante todo, nadie poseerá casa propia, excepto en caso de absoluta necesidad. En segundo lugar, nadie tendrá tampoco ninguna habitación ni despensa donde no pueda entrar todo el que quiera. En cuanto a víveres, [los guardianes] recibirán de los demás ciudadanos, como retribución por su guarda, los que puedan necesitar unos guerreros fuertes, sobrios y valerosos, fijada su cuantía con tal exactitud que tengan suficiente para el año, pero sin que les sobre nada. Vivirán en común, asistiendo regularmente a las comidas colectivas como si estuviesen en campaña. Por lo que toca al oro y la plata, (...) para nada los necesitan”. Traducción de José Manuel Pabón y Manuel Fernández-Galiano, Madrid, 1997. Cf. asimismo en el Político (271 e-272 a. Acerca del llamado "comunismo platónico", cf. el clásico estudio de DAWSON, D., Cities of the Gods. Communist Utopias in the Greek Thought, Oxford, 1992.

Cf. LENS TUERO, op. cit., pp. 174 ss.

55

HES. Op. 112-116. Cf. supra, pp. 3-4.

56 PL. Rep. 372 b. En la Utopía de Moro (e 76-78), por su parte, se refiere que "no hay cena sin música ni sus banquetes carecen de delicadezas y golosinas. Queman resinas perfumadas y especias o perfumes y olores agradables y esparcen suaves ungüentos y aguas”. Traducción de Joaquim Mallafrè Gavaldà, Barcelona, 1984. 
Jenofonte en su República de los lacedemonios ${ }^{57}$. Igualmente este Odiseo:

Cuatro fiestas generales pensaba cada año establecer para el muchacho aún imberbe, para el hombre maduro, para los cuerpos estropeados que se hicieron viejos y para el muerto que se deshizo.

Justo es que el pueblo olvide con las fiestas y el vértigo del baile el salado sudor del quehacer del día. (XV 706-710)

Sin embargo, en un aspecto notable se aparta Kazantzakis de la tradición platónica. Se trata de su actitud hacia los ancianos:

Justo es que cantemos llenos de alegría al anciano que muere; jadeaba, vacío quedó y ya no sirve, en vano come pan; la carne corrompida que descienda a la tierra, a ese gran taller, iy se funda en nuevas y hondas muelas, para poder renovarse! (XV 1010-1013)

Los ancianos son improductivos. Lejos de ser útiles, representan una carga para la sociedad. Nada más lejos del pensamiento de un filósofo que, como Platón, vio cómo su ciudad condenaba y ejecutaba a su maestro septuagenario aunque un sabio educador, utilísimo aún para la polis. Todo lo contrario, abundan en los diálogos platónicos palabras de honra para los ancianos, más todavía si son sabios. En el Parménides Platón describe al viejo filósofo, dos generaciones mayor que Sócrates, y a su discípulo: "Parménides, por cierto, era entonces ya muy anciano; de cabello enteramente canoso, pero de aspecto bello y noble, podía tener unos sesenta y cinco años. Zenón rondaba entonces los cuarenta, tenía buen porte y agradable figura, y de él se decía que había sido el favorito de Parménides (...) Sócrates en ese momento, era aún muy joven" ${ }^{58}$. En las Leyes, Platón dice que "es necesario que todo hombre, niño y mujer consideren que la ancianidad es acreedora a mucho mayor respeto que la juventud, así entre los dioses como entre los hombres que aspiren a vivir largamente y ser felices" ${ }^{59}$. En el Gorgias afirma que Polo

\section{$57 \quad$ JEN. Rep. Lac. XII 7.}

58 PL. Parm. 127 b-c. Traducción de M ${ }^{\mathrm{a}}$ I. de Santa Cruz, Madrid, 2000. Se estima que Sócrates debió tener, en ese momento, unos veinte años.

59 PL. Lg. 879 b. Traducción de José Manuel Pabón y Manuel Fernández-Galiano, Madrid, 1999. 
es "joven e impaciente", neós kaì oxús ${ }^{60}$, y en la República establece que la edad mínima para llegar a ser un rey-filósofo es de cincuenta años ${ }^{61}$, como menos de cincuenta no debe tener el magistrado encargado de supervisar la educación de niños y niñas en la utópica ciudad de Magnesia ${ }^{62}$, según dice en las Leyes ${ }^{63}$. No pocos estudiosos han visto en estas propuestas la visible influencia del régimen espartano ${ }^{64}$. Sin embargo, es posible que esta actitud de desprecio por la senectud entre los pensadores griegos se remonte a la tradición cínica. Sexto Empírico transmite un pasaje del Acerca del deber del estoico Crisipo, de probada influencia cínica, donde afirma textualmente que "cuando mueren los progenitores (tôn gonéôn) hay que hacerles la sepultura más simple, en cuanto que nuestro cuerpo, al igual que las uñas y los cabellos, no es nada para nosotros, ni ciertamente tenemos necesidad del cuidado ni de la importancia que generalmente damos a estas cosas" ${ }^{65}$.

\section{A manera de conclusión}

Se cuenta en la rapsodia XVI, la "ciudad ideal" de Kazantzakis tendrá una brevísima existencia. Un terrible cataclismo la destruirá aún antes de que pueda ser habitada, como también destruyó un cataclismo la ciudad de los Atlantes ${ }^{66}$ y como dicen los historiadores que desapareció la próspera civilización micénica en el siglo IX a.C. Así también en esta Odisea:

Amanecer. Se ha hundido la ciudadela y la boca del monte ya se ha cerrado, y su lengua, la llama, se ha detenido,

saciada;

y risueño el sol apareció sobre unos nimbos flamígeros y se esparció la luz como una rosa por la tierra devastada.

(XVI 270-273)

$60 \quad$ PL. Gorg. 463 e.

61 PL. Rep. 540 a-541 b.

62 Cf. MOORE, K. R., Plato, Politics and a Practical Utopia, London-New York, 2012.

63 PL. $L g .765 \mathrm{~d}$.

64 Cf. BLACKBURN, S., Plato's Republic. A Biography, New York, 2006.

65 SEXT. EMP. Avd. math. IX $194=$ Stoicorum Veterum Fragmenta III 752.

66 PL. Tim. 25 e. 
No faltan autores que quieren asociar el fin de la utopía de Kazantzakis con el entusiasmo y posterior decepción que pudo haber causado en el poeta el auge y consolidación de los diferentes regímenes totalitarios que surgieron en la Europa de los años treinta, y que coinciden con el tiempo en que la Odisea fue compuesta ${ }^{67}$. De hecho, se sabe que la rapsodia XV fue escrita en 1927. Kazantzakis acababa de volver de Moscú, a donde había sido invitado para participar en las celebraciones del décimo aniversario de la Revolución. En realidad, entre 1925 y 1930 el poeta viajará en tres oportunidades a la URSS, permaneciendo allí un total de dos años ${ }^{68}$. En casi todo ese período la rapsodia sufrirá una serie de cambios, enmiendas y correcciones, hasta 1929. Mientras tanto, en la Unión Soviética se consolida el liderazgo de Stalin, caracterizado por la represión y las crueles purgas intestinas en lo político, así como por la implementación de una economía planificada y centralizada y el surgimiento de la Unión Soviética como potencia mundial y como referencia ideológica. El resultado fue el afianzamiento de un régimen totalitario, así como la industrialización y la colectivización económica del país; pero también el Gulag y los millones de deportados y exiliados, a más de las grandes hambrunas que dejaron millones de muertos.

La rapsodia XV de la Odisea de Kazantzakis, la "ciudad ideal" queda como uno de los grades textos utópicos del siglo $\mathrm{XX}$, junto a obras como Nosotros de Yevgeni Zamiatin, Un mundo feliz de Aldous Huxley, Fahrenheit 451 de Ray Bradbury y 1984 de George Orwell. Para decirlo en palabras de Miguel Castillo Didier, también como utopía, la obra encarna "la epopeya y tragedia del hombre contemporáneo" ${ }^{69}$. En ese sentido forma parte de una larga tradición de reflexión sobre el no-lugar, como eutopía y también como distopía, que se remonta a los inicios mismos de la literatura griega y más concretamente al pensamiento de Platón. Con ellos, como con la obra de

67 GONZÁLEZ VAQUERIZO, op. cit., p. 251. En todo caso, como bien argumenta la autora, "novelas como Vida y hechos de Alexis Zorbas, Los hermanos enemigos o El capitán Mijalis, escritas en 1943 la primera y 1953 las segundas, son auténticos alegatos contra la guerra y llamamientos a la hermandad entre los pueblos". Para el proceso de la escritura de la Odisea de Kazantzakis y su valoración en el contexto de la literatura europea y neohelénica, cf. CASTILLO DIDIER, M., La Odisea en la Odisea. Estudios y ensayos sobre la Odisea de Kazantzakis, Santiago de Chile, 2006-2007, pp. 27 ss.

CASTILLO DIDIER, M., "Introducción” en: KAZANTZAKIS, N., La Odisea, Traducción, estudios y síntesis de Miguel Castillo Didier, Santiago de Chile, 2013, pp. 23-24.

69 CASTILlO DIDIER, M., El tiempo, la muerte y la palabra en la Odisea de Kazantzakis, Santiago de Chile, 2017, pp. 22-28. 
Moro, contrajo deudas innegables, pero también con su tiempo y su lugar.

\section{REFERENCIAS BIBLIOGRÁFICAS}

ANNAS, J. (1981). An introduction to Plato's «Republic», New York-Oxford: Oxford University Press.

BLACKBURN, S. (2006). Plato's Republic. A Biography, New York:Glove Press.

GONZÁLEZ VAQUERIZO, H. (2013) "La ciudad ideal en la Odisea de Nikos Kazantzakis", Byzantion Nea Hellas 32.

CASTILLO DIDIER, M. (2017). El tiempo, la muerte y la palabra en la Odisea de Kazantzakis, Santiago: Centro de Estudios Griegos.

--- 2006-2007 La Odisea en la Odisea. Estudios y ensayos sobre la Odisea de Kazantzakis, Santiago: Centro de Estudios Griegos.

JAEGER, W. (1985). Paideia: los ideales de la cultura griega. Traducción de Joaquín Xirau y Wenceslao Roces, México: F. C. E..

KAZANTZAKIS, N. (2013). La Odisea. Traducción, estudios y síntesis de Miguel Castillo Didier, Santiago: Tajamar Editores.

--- (1958) The Odyssey. Translation into English verse, Introduction, Sypnosis and Notes by K. Friar. New York: Simon and Schuster.

LENS TUERO, J. (1996) "La representación de la Edad de Oro desde Hesíodo hasta Pedro Mártir de Anglería”, en GARCÍA GONZÁLEZ, J. y POCIÑA PÉREZ, A. (eds.), Pervivencia y actualidad de la cultura clásica, Granada.

LENS TUERO, J. y CAMPOS DAROCA, J. (2000) Utopías del mundo antiguo. Antología de textos, Madrid, Alianza Editorial.

MOORE, K. R. (2012) Plato, Politics and a Practical Utopia. Social Constructivism and Civic Planning in the Laws, London-New York: Bloomsbury Publishing.

MUÑOZ JIMÉNEZ, J. M. (1996) La ciudad como obra de arte. Las claves del urbanismo en la Grecia antigua. Madrid: Ediciones Clásicas.

NAVA CONTRERAS, M. (2009) Del concepto de polis entre los antiguos Griegos. Mérida: Universidad de Los Andes.

--- (2007) Estudios sobre pensamiento antiguo. Mérida: Universidad de Los Andes.

PRADEAU, J.-F. (2001) «L'Atlantide de Platon, l'utopie vraie». Elenchos, 2001, fasc. 1.

SAVATER, F. (2001) Idea de Nietzsche. Barcelona : Ariel.

VIDAL-NAQUET, P. (2005) L'Atlantide. Petite histoire d'un mythe Platonicien. Paris : Société d'Édition Les Belles Lettres. 